\title{
Transient stability improvement by using PSS and increasing inertia of synchronous machine
}

\author{
Pushpalata Khalkho, Arvind Kumar Singh \\ Electrical Engg. Deptt. B.I.T Sindri, Dhanbad, Govt. of Jharkhand-828123, India \\ Email address: \\ Pushpi215@gmail.com (P. Khalkho), singharvindk67@gmail.com (A. K. Singh)
}

To cite this article:

Pushpalata Khalkho, Arvind Kumar Singh. Transient Stability Improvement by Using PSS and Increasing Inertia of Synchronous Machine. American Journal of Electrical Power and Energy Systems. Vol. 3, No. 2, 2014, pp. 45-49. doi: 10.11648/j.epes.20140302.15

\begin{abstract}
The main objective of this paper is to perform transient stability analysis using the electrical power system design and analysis software namely E-Tap. The purpose of performing transient stability on the power system is to study the stability of a system under various disturbances. The stability of the power system is the ability of generators to remain in synchronization even when subjected to disturbance. In this paper a 9-bus test system is considered fig.(1). Improvement of transient stability by coordination of PSS (Power System Stabilizer) and increasing inertia of synchronous machine has been observed.
\end{abstract}

Keywords: Power System Stabilizer, ETAP-Software, Transient Stability, Three Phase Fault

\section{Introduction}

The power system stability is an electromechanical phenomenon, it is thus defined as the ability of designated synchronous machine in the system to remain in synchronism with one another following disturbance such as fault and fault removal at various locations in the system. It also indicates the ability of induction motors in the system to maintain torque to carry load following there disturbances.

Power system stability is the property of a power system that insures the system remains in electromechanical equilibrium throughout any normal and abnormal operating condition.

The term stability can be interpreted as maintenance of synchronism. The transient disturbances are caused by the changes in loads, switching operations, particularly faults and loos of excitation. Thus, maintenance of synchronism during steady state condition and regaining of synchronism or equilibrium after a disturbance are prime importance to the electrical utilities.[1].

The stability of an interconnected power system is its ability to return to normal or stable operation after having been subjected to some form of disturbance. Conversely, instability means a condition denoting loss of synchronism or falling out of step.

\subsection{Transient Stability}

A synchronous power system has transient stability if after a large sudden disturbance; it can regain and maintain synchronism. A sudden large disturbance includes application of fault, clearing of fault, switching on and off the system element (transmission line, transformers, generator, loads, bus etc.)

\subsection{Transient Stability Analysis}

Transient stability is the ability of the power system to maintain synchronism when subjected to a severe transient disturbance. The resulting system response involves large excursions of generator rotor angle and is influenced by the nonlinear power-angle relationship. Stability depends on both the initial operation state of the system and the severity of the disturbance. Usually, the system is altered so that the post disturbance steady-state operation differs from

That prior to the disturbance.[1]

A fault in the system will lead to instability and the machine will fall out of synchronism. If the system can't sustain till the fault is cleared, then the whole system will be in stabilized. During the instability not only the oscillation in rotor angle around the final position goes on increasing but also the change in angular speed. In such a situation the system will never come to its final position. The unbalanced condition or transient condition may leads to instability where the machines in the power system fall 
out of synchronism.

The system is subjected to a large variety of disturbances. The switching on and off of an appliance in the house is also a disturbance depending upon the size and capability of interconnected system. Large disturbances such as lightning strokes, loss of transmission line carrying bulk power do occur in the system. Therefore transient stability is defined as the ability of the power system to survive the transition following the large disturbance and to reach an acceptable operating condition.

The physical phenomenon that occurs during a large disturbance is that there will be an imbalance between the mechanical power input and the electrical power output. This will tend to run the generator at high speed. The result will be the loss of synchronism of the generator and the machine will be disconnected from the system. This phenomenon is referred to as a generator going out of step.[1].

\section{Software Used}

The simulation software used here is E-Tap or Electrical Transient Stability Analysis Program by Operation Technology. There are different analyses that can be performed on a bus system using this software. Load flow analysis, short Circuit Analysis, Arc Flash analysis, Harmonic Analysis, Transient stability analysis.

E-TAP is a fully graphical enterprise package that runs on Microsoft windows 2003,2008, XP, vista, and 7 operating system. E-TAP is the post comprehensive analysis tool for the design and testing of power system available. Using its standard offline simulation modules, ETAP com utilize real time operating data for advance monitoring, real time simulation, optimization, energy management system, and high-speed intelligent load shedding.

E-TAP software easily create and edit graphical one-line diagrams (OLD) underground cable raceway system (UGS) ,three-dimensional cable system , advanced timecurrent coordination and selectivity plots, geographic information system schematics (GIS), as well as three dimensional ground grid system (GPS) the programmer has been designed to incorporate to three key concepts.

\subsection{Power System Stabilizer}

The power system stabilizer (PSS) uses auxiliary stabilizing signal to control the excitation system so as to improve power system dynamic performance commonly use input signal to the power system stabilizer are shaft speed, terminal frequency and power. Power system dynamic performance is improved by the damping of system oscillations. This is a very effective method of enhancing small signal stability performance. PSS based on shaft speed signal has been used successfully on hydraulic units since the mid-1960s. A technique developed to derive a stabilizing signal from measurement of shaft speed of a hydraulic unit. The application of shaft speed-based stabilizers to thermal units requires a careful consideration of the effects on torsional oscillations. The stabilizer, while damping the rotor oscillation, can cause instability of the torsional modes.[2-3]

Thermal frequency has been used as the stability signal several (PSS) power system stabilizer application. Normally, the terminal frequency signal is used directly as the stabilizer input signal. In some cases, terminal voltage and current are used to derive the frequency of a voltage behind a simulated machine reactance so as to approximate the machine rotor speed.[3].

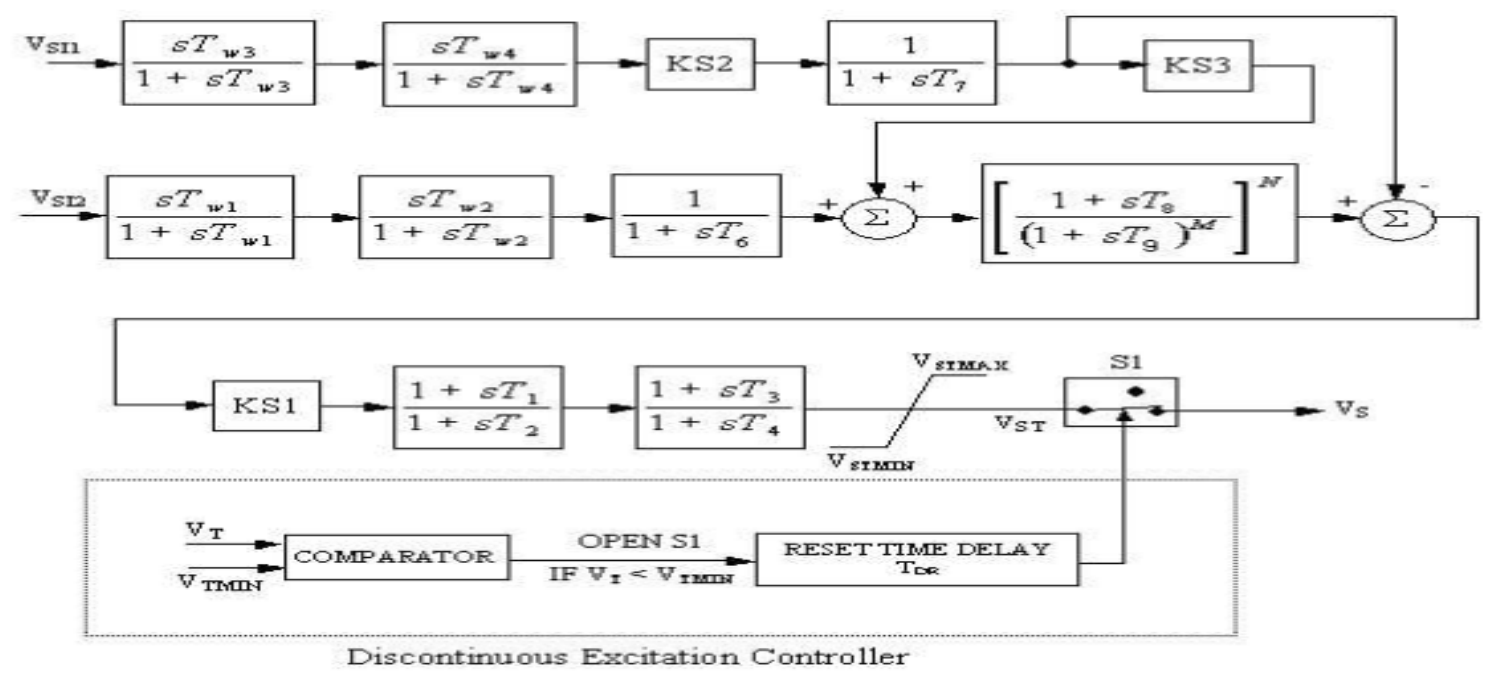

Fig (1) IEEE Type-2 PSS(PSS2A).

\subsection{Exciter}

The based function of exciter system is to provide direct current to the synchronous machine field winding. The excitation system performs control and protective essential to the satisfactory performance of the power system by 
controlling the field voltage and the field current. IEEE DC1 type exciter are used in this model.

\section{Test System}

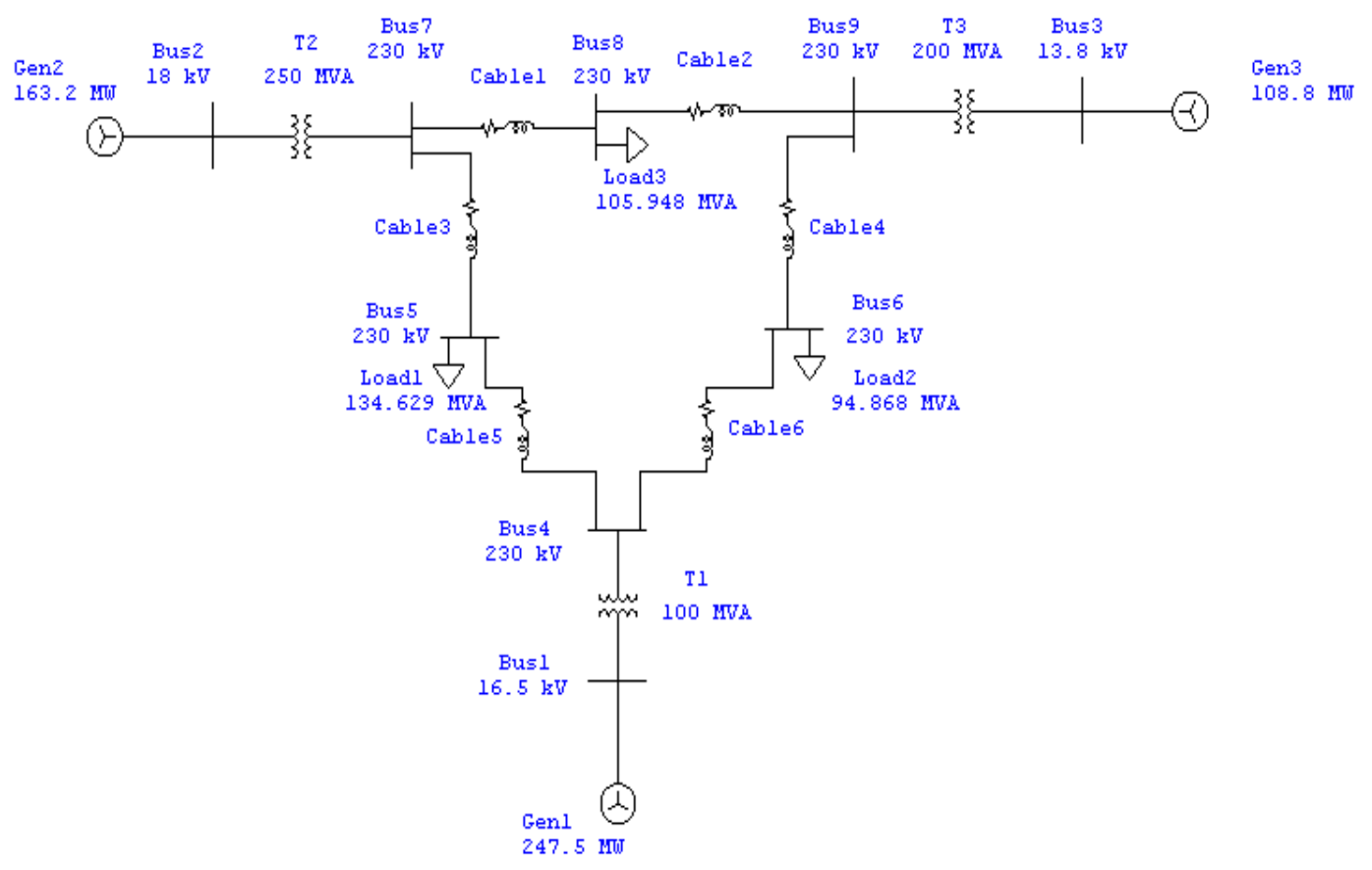

Fig (2)Test system.

\subsection{Input Data}

Table 1. Synchronous machine parameter input data.

\begin{tabular}{|c|c|c|c|c|c|c|c|c|c|c|c|c|c|c|c|}
\hline \multicolumn{3}{|c|}{ Machine } & \multicolumn{2}{|c|}{ Rating } & \multicolumn{8}{|c|}{ Positive sequence impedance $(\%)$} & \multicolumn{3}{|c|}{ Zero seq. Z(\%) } \\
\hline ID & Type & Model & MVA & KV & $\mathrm{R}_{\mathrm{a}}$ & $X_{d} "$ & $\mathrm{X}_{\mathrm{d}}^{\prime}$ & $\mathrm{X}_{\mathrm{d}}$ & $\mathrm{X}_{\mathrm{q}} ”$ & $\mathrm{X}_{\mathrm{q}}^{\prime}$ & $\mathrm{X}_{\mathrm{q}}$ & $\mathrm{X} 1$ & $\mathrm{X} / \mathrm{R}$ & $\mathrm{R}_{0}$ & $\mathrm{X}_{0}$ \\
\hline GEN1 & Generator & $\begin{array}{l}\text { Subtransient, } \\
\text { Round-Rotor }\end{array}$ & 291.17 & 16.5 & 1 & 19 & 28 & 155 & 19 & 65 & 115 & 15 & 7 & 1 & 7 \\
\hline GEN2 & Generator & $\begin{array}{l}\text { Subtransient, } \\
\text { Round-Rotor }\end{array}$ & 192 & 18 & 1 & 19 & 28 & 155 & 19 & 65 & 115 & 15 & 7 & 1 & 7 \\
\hline GEN3 & Generator & $\begin{array}{l}\text { Subtransient, } \\
\text { Round-Rotor }\end{array}$ & 128 & 13.8 & 1 & 19 & 28 & 155 & 19 & 65 & 115 & 15 & 7 & 1 & 7 \\
\hline
\end{tabular}

Table 2. dynamic parameters of synchronous machine input data.

\begin{tabular}{|c|c|c|c|c|c|c|c|c|c|c|c|c|c|c|}
\hline \multirow{2}{*}{$\begin{array}{c}\text { Machine } \\
\text { ID }\end{array}$} & \multirow{2}{*}{$\begin{array}{c}\begin{array}{c}\text { Connected } \\
\text { Bus }\end{array} \\
\text { ID }\end{array}$} & \multicolumn{4}{|c|}{ Time constant (sec.) } & \multicolumn{5}{|c|}{$\begin{array}{c}\text { H(sec.),D(MWpu/Hz) \& } \\
\text { Saturation }\end{array}$} & \multicolumn{2}{|c|}{$\begin{array}{c}\text { Generator or } \\
\text { loading }\end{array}$} & \multicolumn{2}{|c|}{ Grounding } \\
\hline & & $\mathrm{T}_{\mathrm{d} 0} "$ & $\mathrm{~T}_{\mathrm{d} 0}$ & $\mathrm{~T}_{\mathrm{q} 0} "$ & $\mathrm{~T}_{\mathrm{q} 0}$, & $\mathrm{H}$ & $\% \mathrm{D}$ & S100 & S120 & Sbreak & MW & MVar & Conn. & Type \\
\hline GEN1 & BUS1 & 0.035 & 6.5 & 0.035 & 1.25 & 3 & 0 & 1.07 & 1.18 & 0.8 & 0 & 0 & wye & solid \\
\hline GEN2 & BUS2 & 0.035 & 6.5 & 0.035 & 1.25 & 3 & 0 & 1.07 & 1.18 & 0.8 & 0 & 0 & wye & solid \\
\hline GEN3 & BUS3 & 0.035 & 6.5 & 0.035 & 1.25 & 3 & 0 & 1.07 & 1.18 & 0.8 & 0 & 0 & wye & solid \\
\hline
\end{tabular}

Table 3. Mechanical parameters of synchronous machine input data.

\begin{tabular}{|c|c|c|c|c|c|c|c|c|c|c|c|c|c|}
\hline \multicolumn{2}{|c|}{ Machine } & \multicolumn{3}{|c|}{ Generator/Motor } & \multicolumn{3}{|c|}{ Coupling } & \multicolumn{3}{|c|}{ Prime mover/load } & \multicolumn{3}{|c|}{ Equivalent Total } \\
\hline ID & Type & RPM & $\mathrm{WR}^{2}$ & $\mathrm{H}$ & RPM & $\mathrm{WR}^{2}$ & $\mathrm{H}$ & RPM & $\mathrm{WR}^{2}$ & $\mathrm{H}$ & $\mathrm{RPM}$ & $\mathrm{WR}^{2}$ & $\mathrm{H}$ \\
\hline GEN1 & GEN & 1500 & 1680671.88 & 3 & 1800 & 0 & 0 & 1800 & 0 & 0 & 1500 & 1680671.88 & 3 \\
\hline GEN2 & GEN & 1500 & 1108225 & 3 & 1800 & 0 & 0 & 1800 & 0 & 0 & 1500 & 1108225 & 3 \\
\hline GEN3 & GEN & 1500 & 738817 & 3 & 1800 & 0 & 0 & 1800 & 0 & 0 & 1500 & 738817 & 3 \\
\hline
\end{tabular}

WR2: kg-m² H: MW-Sec/MVA 
Table 4. Power system stabilizer input data (Type-PSS2A).

\begin{tabular}{|c|c|c|c|c|c|c|c|c|c|c|c|c|c|}
\hline Gen. ID & VSI1 & VSI2 & KS1 & KS2 & KS3 & VSTMax & VSTMin & VTMin & VDR & Tw1 & Tw2 & Tw3 & Tw4 \\
\hline \multirow{3}{*}{ GEN1 } & & & $\mathrm{N}$ & $\mathrm{M}$ & $\mathrm{T} 1$ & $\mathrm{~T} 2$ & T3 & $\mathrm{T} 4$ & T5 & T6 & $\mathrm{T} 7$ & $\mathrm{~T} 8$ & \\
\hline & Elec.power & Speed & 20 & 0.001 & 1 & 0.2 & -0.066 & 0 & 0.2 & 10 & 10 & 10 & 10 \\
\hline & & & 4 & 2 & 0.16 & 0.02 & 0.16 & 0.02 & 0 & 0 & 0.3 & 0.15 & \\
\hline \multirow[t]{2}{*}{ GEN2 } & Elec.power & Speed & 20 & 0.001 & 1 & 0.2 & -0.066 & 0 & 0.2 & 10 & 10 & 10 & 10 \\
\hline & & & 4 & 2 & 0.16 & 0.02 & 0.16 & 0.02 & 0 & 0 & 0.3 & 0.15 & \\
\hline GEN3 & Elec.power & Speed & 20 & 0.001 & 1 & 0.2 & -0.066 & 0 & 0.2 & 10 & 10 & 10 & 10 \\
\hline
\end{tabular}

Table 5. Exciter input data (Type-DC1).

\begin{tabular}{|c|c|c|c|c|c|c|c|c|c|c|c|c|c|c|}
\hline $\begin{array}{l}\text { Machine } \\
\text { ID }\end{array}$ & $\begin{array}{l}\text { Control } \\
\text { bus ID }\end{array}$ & $\begin{array}{c}\text { KA } \\
\text { Efd }_{\max }\end{array}$ & $\mathbf{K E}$ & $\mathbf{K F}$ & TA & TB & TC & TE & TF & TR & $\mathbf{V} \mathbf{R}_{\max }$ & $\mathbf{V} \mathbf{R}_{\max }$ & $\mathbf{S E}_{\max }$ & SE.75 \\
\hline Gen1 & Bus1 & $\begin{array}{c}46 \\
2.63\end{array}$ & 0.05 & 0.1 & 0.06 & 0 & 0 & 0.46 & 1 & 0.005 & 1 & -0.9 & 0.33 & 0.1 \\
\hline Gen2 & Bus2 & $\begin{array}{c}46 \\
2.63\end{array}$ & 0.05 & 0.1 & 0.06 & 0 & 0 & 0.46 & 1 & 0.005 & 1 & -0.9 & 0.33 & 0.1 \\
\hline Gen3 & Bus3 & $\begin{array}{c}46 \\
2.63\end{array}$ & 0.05 & 0.1 & 0.06 & 0 & 0 & 0.46 & 1 & 0.005 & 1 & -0.9 & 0.33 & 0.1 \\
\hline
\end{tabular}

\section{Simulation Result and Discussion}

Transient stability study is essentially an action driven time-domain simulation. Actions should be specified at different time instants (events).When to simulate the system response for existing events, such as a recorded fault in the system, we use this type of action, because the recorded fault occurring time and duration are known.

In this paper we discuss the transient stability performance with PSS (Power system stabilizer) and by increasing inertia of synchronous machine. In this system any one method of improving stability may not be adequate. So combinations of two methods are used in this system. Here we use accelerated gauss-seidel for initial load flow calculation. In which maximum number of iteration is 2000 and Solution Precision for the Initial LF is 0.0000010000 And Time Increment for Integration Steps $(\Delta \mathrm{t})$ is 0.0100 and acceleration factor for the initial load flow is 1.45. Initial inertia of the installed machine was $3 \mathrm{MW}-\mathrm{Sec} / \mathrm{MVA}$ and after increasing its inertia is $7 \mathrm{MW}-\mathrm{Sec} / \mathrm{MVA}$. The overall performance of the power system, Solutions to the stability problem of one category should not be affected at the expense of another category. So inertia of the machine is not so much increased because after increasing inertia of machine rotor will be heavier.

The different plot for Gen-1. When a three phase fault on bus-5 at $0.350 \mathrm{sec}$ and cleared at $0.600 \mathrm{sec}$ are shown below in fig. comparisons each-other.

Electrical powers of gen-1, fig.(3) and fig.(4) shows Electrical power (MW) Vs. time(sec.).Electrical power with inertia and Electrical power with PSS2A, increasing inertia are Comparison with initial electrical power.

The electromechanical oscillation for generator electrical power is reduced and steady state power is improved when used PSS2A and increasing inertia of synchronous machine seen in fig.(4). Terminal current of gen-1, fig.(5) and fig.(6)Terminal current (Amp)Vs time(sec.). Terminal current with inertia and terminal current with PSS2A, increasing inertia are comparison with initial terminal current of synchronous machine.

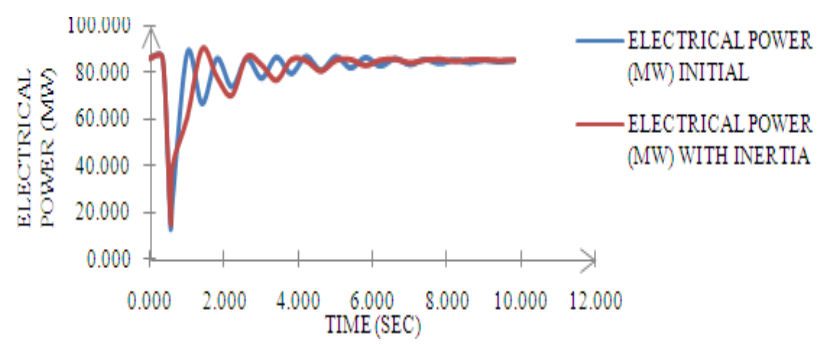

Fig (3) Electrical power ( $m w$ ) initial \& Electrical power ( $m w)$ with inertia.

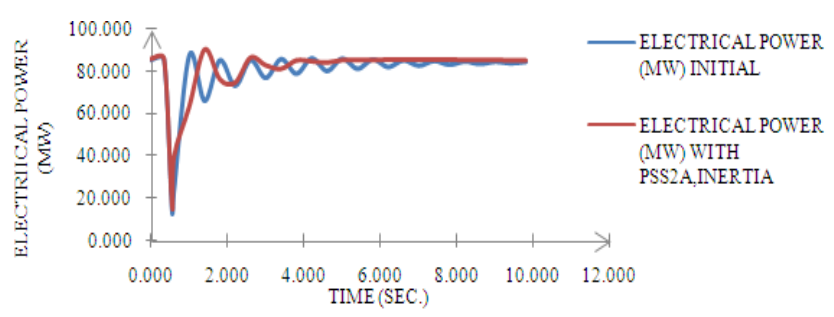

Fig (4) Electrical power ( $m w$ ) initial \& Electrical power ( $m w$ ) with PSS2A, inertia.

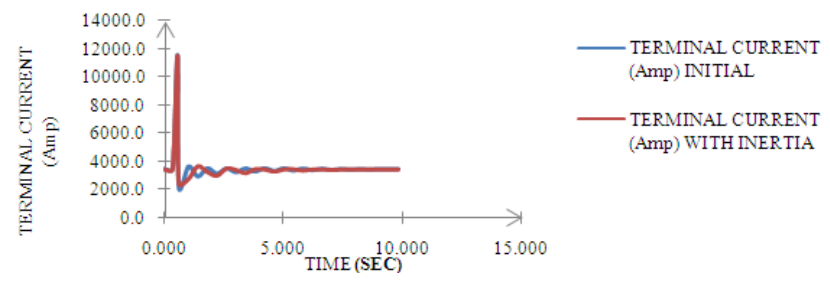

Fig (5) Terminal current (Amp) initial \& Terminal current (Amp) with inertia.

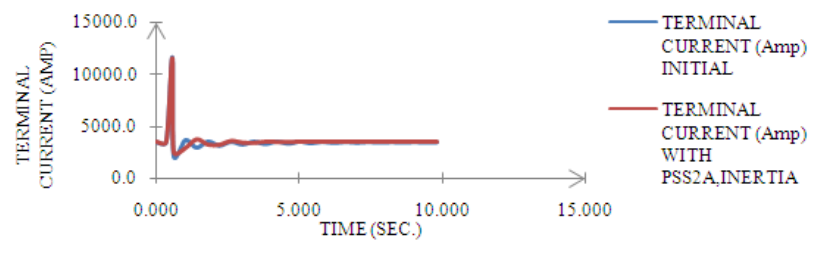

Fig (6)Terminal current (Amp) initial \& Terminal current (Amp) with PSS2A, inertia. 
The oscillation in terminal current is reduced when used PSS2A and increasing inertia of synchronous machine seen in fig.(6).

Field current of gen-1, fig. (7)and fig.(8) Field current (P.U) Vs time (sec.). Field current with inertia and Field current with PSS2A, increasing inertia are comparison with initial field current of synchronous machine.

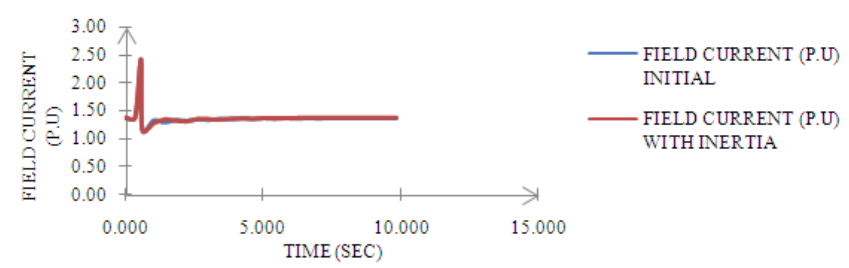

Fig(7) Field current (P.U) initial \&Field current (P.U) with inertia.

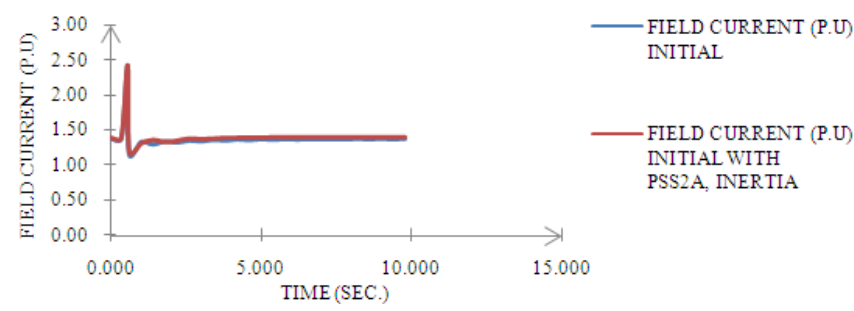

Fig (8) Field current (P.U) initial \& Field current (P.U) with PSS2A, inertia.

Oscillation of Field current is also reduced when increasing inertia. Field current are not change when we increasing inertia and PSS2A, increasing inertia in fig.(7) and fig.(8).

Field voltage of gen-1, fig.(9) Field voltage (P.U) Vs time (sec.).Field voltage(P.U) with initial and field voltage with PSS2A, increasing inertia of synchronous machine are Comparison. Field voltage are constant in initial and oscillated initially when used PSS2A, increasing inertia but after some time it is constant and within limit as shown in fig.(9).

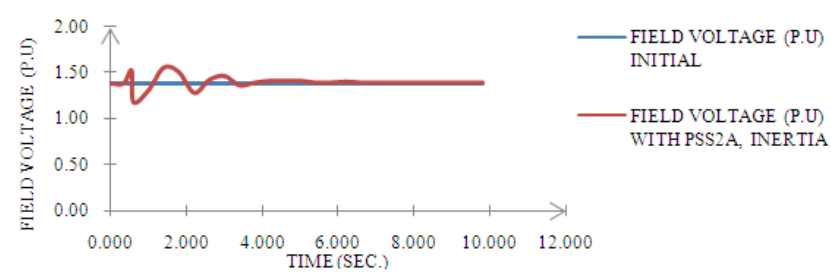

Fig (9) Field voltage (P.U) initial \& Field voltage (P.U) with PSS2A, inertia.

\section{Conclusion}

Transient stability Performances of the multi machine system by using (PSS) power system stabilizer and other method has been compared. When we used (PSS)power systemstabilizer and increasing inertia then electromechanical oscillation has been achieved better response. The transient stability improvement is not sufficient by using one method. So here we use these two combined method for improving stability. E-Tap provides transient stability study results at all different level of detail, depending on our requirement.

\section{References}

[1] Kundur, P., Power system stability and control, McGrawHill, New York, 1994.

[2] P. Kundur, M. Klein, G.J. Rogers, and M.S. Zywno, "Application of power system stabilizers for Enhancement of overall system stability," IEEE Trans., Vol. PWRS-4, No.2, PP.614- 626,May 1989.

[3] P. Kundur, D.C. Lee and H.M. Zein EL-Din,” Power system stabilizer for thermal units: Analytical Techniques and onsite Validation," IEEE Trans., Vol.PAS-100,PP.8195,January 1981.

[4] IEEE Committee Report "Proposed Excitation system Definition for synchronous machine," IEEE Trans., Vol. PAS- 88, PP.1228-1258,August 1969.

[5] IEEE/CIGRE Joint task force on stability terms and definitions, 'Definition and classification of Power System Stability,' IEEE trans. Power System, Vol. 19,No.2, PP. 1387-1401, May 2004.

[6] IEEE standard Definitions for excitation system for synchronous machines IEEE standard.

[7] Kamwa I. ,Grandin R. and Trudal G. , 'IEEE PSS2B versus PSS4B: The limit of performance of modem Power System Stabilizers, IEEE Trans. Power System, Vol., NO.2,PP.903915,May 2005.

[8] P. Kundur and D.C lee "Advanced excitation control for power system stability Enhancement," CIGRE Paper 38- 01, paris, France 1986.

[9] E. W. Kimbark, power system stability, Vol.3: Synchronous machines Jon Wiley \&Sons, 1956.

[10] P.K. Iyambo, R. Tzonova, "Transient Stability Analysis of the IEEE 14-Bus Electrical Power System”, IEEE Conf. 2007

[11] K.R. Padiyar, 'Power system Dynamics-Stability and control,' second Edition, (Hyderabad), B.S. Publication, 2002.

[12] IEEE Task force, "Proposed terms and Definition for power system stability," IEEE trans.,Vol.PAS-101,pp.1894-1898, July 1982.

[13] F.P. deMello and C. Corcordia, "Concepta of Synchronous Machine Stability as Affected by Excitation control," IEEE Trans., Vol. PAS-88, PP.316-329, April 1969. 